\title{
ALGUNAS REFERENCIAS OFTALMOLÓGICAS EN LA LITERATURA ESPAÑOLA DE PRINCIPIOS DEL S. XX
}

\author{
BARBÓN JJ ${ }^{1}$, SAMPEDRO A ${ }^{1}$, ÁLVAREZ-SUÁREZ ML ${ }^{2}$
}

La lectura de algunos libros centrados en el primer tercio del s. XX, un período considerado como una «edad de plata» en la literatura española, nos permite un acercamiento (aunque anecdótico) a la oftalmología de la época utilizando referencias literarias. Para ello vamos a recurrir a 2 literatos que fueron médicos y escribieron relatos autobiográficos, Pío Baroja y Felipe Trigo, a los que vamos a añadir la aportación de Santiago Ramón y Cajal, que también dio a la luz obras literarias, y de Armando Palacio Valdés, que utilizó la figura del médico como protagonista de algunas de sus novelas.

Felipe Trigo (1864-1916), hoy casi olvidado, fue nuestro escritor más popular durante los primeros lustros del s. XX. Había estudiado medicina en Madrid y ejercido de médico rural, y aunque luego abandonó la medicina por la literatura, recogió esas experiencias autobiográficas en sus novelas En la carrera (1906) y El médico rural (1912). En la primera, subtitulada «Un buen chico estudiante en Madrid» narra las aventuras de su alter ego, Esteban, con el trasfondo social de pobreza y discriminación de la mujer, en un Madrid licencioso, juerguista y plagado de sífilis que era la perdición de los estudiantes. Aquí nos describe como uno de sus amigos, también estudiante de medicina, estaba liado con la patrona de la pensión que tenía «Blefaritis ¿sabes? ... es que le salen las pestañas hacia dentro y se las tengo que arrancar...». Hace mención a la cirugía de cataratas, sin más detalle, al hablar de la ausencia de una viejecita que hacía de celestina en sus amoríos en el pueblo «... supo que estaba en el Hospital, que la habían curado del asma y ahora de cataratas...». En la segunda novela, donde el estudiante ejerce ahora en su primer destino como médico rural, seguramente tomado de su experiencia personal, nos relata el caso de un muchacho con glaucoma que se complica con endoftalmitis: «El muchacho de la noche a la mañana, se vió aquejado de agudísimos dolores que nada podía calmar y pasábase las horas en un grito. Al principio este enfermo tenía el ojo hinchado, duro y casi blanco; pero veía con el los bultos... luego había ido abultándosele, poniéndosele sensible y adquiriendo una tensión alarmantísima... tanto se le inflamó, que no podía cerrar los párpados, y al lado de la niña, borrada en la confusión de aquella masa lamentable, iniciábase una ampolla de pus, un absceso que dejó al médico aterrado». A los pocos días el ojo se evisceró espontáneamente, aliviándose el dolor pero en Esteban quedó un profundo sentimiento de ineptitud profesional y pensaba que «Para su baldón, quedaría... el niño aquel, el tuerto aquel, cada vez que se lo tropezara por las calles». En su obra más conocida, Jarrapellejos (1914), donde nos presenta a un cacique extremeño capaz de controlar a su entorno rural usando todo tipo de artimañas, hace una referencia jocosa sobre la conjuntivitis neonatal. «Sabia asimismo de unos niños a pique de quedarse ciegos por oftalmías

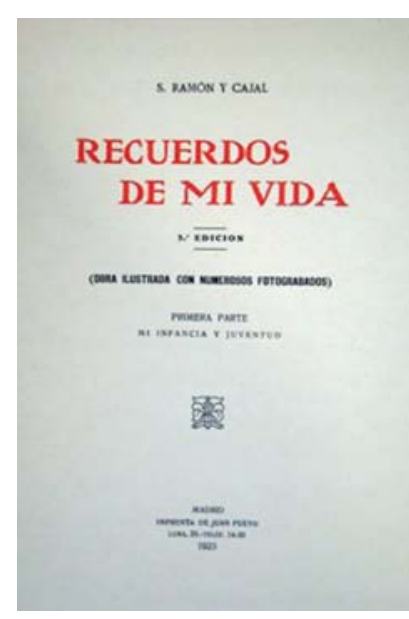

Fig. 1: Recuerdos de mi vida de Cajal (Primera parte. Mi infancia y juventud).

\footnotetext{
${ }^{1}$ Licenciado en Medicina. Servicio de Oftalmología. Hospital San Agustín de Avilés. Asturias. España. E-mail: jjbarbon@telecable.es

2 Doctor en Medicina. Servicio de Oftalmología. Hospital Álvarez-Buylla de Mieres. Asturias. España.
} 
purulentas contraídas al nacer, de la honrada madre gonorreica sin saberlo».

Ramón y Cajal (1852-1934), nuestro más ilustre científico, que también escribió buena literatura fuera del campo de la histopatología, aporta interesantes referencias oculares en algunos de sus libros. En Mi infancia y juventud (1901), nos describe un accidente ocular que le ocurrió en su adolescencia rebelde y montaraz. Contando con unos 11 años de edad había construido un cañón de madera con una espita de bronce, y tras cargarlo con pólvora fue disparado, explotando en múltiples fragmentos que lo hirieron a él y a su hermano Pedro: «Ignoro como no perdí la vista, pues una partícula metálica penetró en mi ojo, produjo una seria inflamación y dejó en el iris señal indeleble». Se trata aparentemente de un cuerpo extraño intraocular, parece que con un orifico de entrada en el iris, sin consecuencias posteriores. Cuanto podría haber cambiado la historia personal de Cajal y de la ciencia española de haber sufrido una lesión ocular severa que le hubiera limitado su visión binocular, tan necesaria en el manejo del microscopio. En Charlas de Café (1921), colección de pensamientos, anécdotas y confidencias personales expuestas en sus tertulias de café, nos deja esta reflexión: «Nada me apena más que la ceguera de ciertos ancianos. Al ver sus pupilas opacas, evoco sin querer al reo a quien se le vendan los ojos antes de morir». Pero será en El mundo visto a los 80 años (Impresiones de un arteriosclerótico), de 1934 (el año de su muerte), libro sobre las limitaciones físicas, tribulaciones y consuelos del anciano, donde nos dedica un capítulo entero a la decadencia visual. Cajal caracteriza tres deterioros seniles en cuanto a la visión: la presbicia, la hipermetropía y la disminución de agudeza visual. La imposibilidad de lectura a partir de los 45 o 50 años ya es explicada por el endurecimiento del cristalino y/o la pérdida de función del músculo acomodador. La hipermetropía que padecía el propio autor, sumada a la presbicia, debía resolverla mediante «un equipo óptico complicado, antiparras para leer, antiparras para ver de lejos y antiparras para enfocar los escaparates de las librerías». La disminución de la agudeza, que llama acuidad visual, referida como la incapacidad de lectura de libros y periódicos de tipografía diminuta preocupa a nuestro histólogo, quién posee colecciones de obras que no puede consultar. «Y menos mal si una catarata senil o un desprendi- miento de retina no bajan definitivamente el telón sobre el mágico escenario de mundo» concluye.

Armando Palacio Valdés (1853-1938), otro de los novelistas españoles más celebres de su tiempo, escribió Papeles del doctor Angélico (1911) y Años de juventud del doctor Angélico (1918). El autor, que no era médico, compone unas memorias sin entrar en cuestiones clínicas y se centra en la vida estudiantil de la capital con el tema de fondo de la llamada actualmente violencia de género. La esposa maltratada de los Años de juventud del doctor Angélico acaba arrojando un frasco de ácido sulfúrico (el famoso vitriolo) al rostro de su marido, al que ocasiona la ceguera total. Al final, aunque la mujer es declarada inocente, según los cánones de la novela amorosa de la época debe pagar su crimen y muere cuando escucha casualmente a un ciego cantar en su retiro campestre: su antiguo marido que pide limosna cantando canciones populares de pueblo en pueblo. Era una creencia aceptada hace un siglo que la enfermedad y la muerte podían ser causadas por dramas y sucesos amorosos.

Pío Baroja y Nessi (1872-1956), en sus extensas memorias tituladas «Desde la última vuelta del camino» (1944-1949), concretamente en el capítulo «De médico de pueblo» ubicado en la tercera parte «Familia, infancia y juventud» nos relata un episodio muy significativo sobre la práctica azarosa e irregular de la oftalmología en aquellos años. Baroja sólo ejerció la medicina unos meses, tras acabar la carrera, en la villa de Cestona (Guipúzcoa) en 1893. Allí se encontró con la hostilidad del otro médico titular y una falta de vocación personal, pues no se consideraba un buen clínico y era un escéptico profundo en la práctica de la profesión; ambas circunstancias lo alejarían de la medicina ganando, a cambio, un literato. Este colega con mala ley, más versado en cirugía «Una vez me propuso operar a uno de cataratas.

- ¿Lo ha hecho usted antes? -le pregunté

-No, pero alguna vez hay que empezar

-No, entonces yo no colaboro. Busque usted a otro ayudante.»

Este episodio no aparece -ni aporta ningún comentario sobre cuestiones oculares- en El árbol de la ciencia (1911), su mejor novela, donde trasladó muchas experiencias personales tomadas de sus años de estudiante de medicina y del breve periodo en que ejerció como médico rural. 